\title{
Article \\ Ultrathin Leaf-Shaped CuO Nanosheets Based Sensor Device for Enhanced Hydrogen Sulfide Gas Sensing Application
}

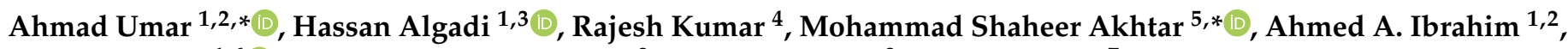 \\ Hasan Albargi $1,6 \oplus$, Mohsen A. M. Alhamami ${ }^{2}$, Turki Alsuwian ${ }^{3}$ and Wen Zeng ${ }^{7}$ \\ 1 Promising Centre for Sensors and Electronic Devices (PCSED), Najran University, Najran 11001, Saudi Arabia; \\ hassan.algadi@gmail.com (H.A.); ahmedragal@yahoo.com (A.A.I.); albargih@yahoo.com (H.A.) \\ 2 Department of Chemistry, Faculty of Science and Arts, Najran University, Najran 11001, Saudi Arabia; \\ maalhammami@nu.edu.sa \\ 3 Department of Electrical Engineering, College of Engineering, Najran University, Najran 11001, Saudi Arabia; \\ tmalsuwian@nu.edu.sa \\ 4 Department of Chemistry, Jagdish Chandra DAV College Dasuya, Punjab 144205, India; rk.ash2k7@gmail.com \\ 5 New \& Renewable Energy Material Development Center (NewREC), Jeonbuk National University, \\ Jeonbuk 56332, Korea \\ 6 Department of Physics, Faculty of Science and Arts, Najran University, Najran 11001, Saudi Arabia \\ 7 College of Materials Science and Engineering, Chongqing University, Chongqing 400044, China; \\ wenzeng@cqu.edu.cn \\ * Correspondence: ahmadumar786@gmail.com or umahmad@nu.edu.sa (A.U.); shaheerakhtar@jbnu.ac.kr (M.S.A.)
}

Citation: Umar, A.; Algadi, H.; Kumar, R.; Akhtar, M.S.; Ibrahim, A.A.; Albargi, H.; Alhamami, M.A.M.; Alsuwian, T.; Zeng, W. Ultrathin Leaf-Shaped CuO Nanosheets Based Sensor Device for Enhanced Hydrogen Sulfide Gas Sensing Application. Chemosensors 2021, 9, 221. https://doi.org/10.3390/

chemosensors 9080221

Academic Editors: Shaolin Zhang and Fang Xu

Received: 7 July 2021

Accepted: 5 August 2021

Published: 11 August 2021

Publisher's Note: MDPI stays neutral with regard to jurisdictional claims in published maps and institutional affiliations.

Copyright: (c) 2021 by the authors. Licensee MDPI, Basel, Switzerland. This article is an open access article distributed under the terms and conditions of the Creative Commons Attribution (CC BY) license (https:// creativecommons.org/licenses/by/ $4.0 /)$.
Abstract: Herein, a simple, economical and low temperature synthesis of leaf-shaped CuO nanosheets is reported. As-synthesized $\mathrm{CuO}$ was examined through different techniques including field emission scanning electron microscopy (FESEM), energy dispersive spectroscopy (EDS), transmission electron microscopy (TEM), high-resolution TEM (HRTEM), X-ray diffraction (XRD), fourier transform infrared spectroscopic (FTIR) and Raman spectroscopy to ascertain the purity, crystal phase, morphology, vibrational, optical and diffraction features. FESEM and TEM images revealed a thin leaf-like morphology for $\mathrm{CuO}$ nanosheets. An interplanar distance of $\sim 0.25 \mathrm{~nm}$ corresponding to the (110) diffraction plane of the monoclinic phase of the $\mathrm{CuO}$ was revealed from the HRTEM images XRD analysis indicated a monoclinic tenorite crystalline phase of the synthesized CuO nanosheets. The average crystallite size for leaf-shaped $\mathrm{CuO}$ nanosheets was found to be $14.28 \mathrm{~nm}$. Furthermore, a chemo-resistive-type gas sensor based on leaf-shaped $\mathrm{CuO}$ nanosheets was fabricated to effectively and selectively detect $\mathrm{H}_{2} \mathrm{~S}$ gas. The fabricated sensor showed maximum gas response at an optimized temperature of $300{ }^{\circ} \mathrm{C}$ towards $200 \mathrm{ppm} \mathrm{H}_{2} \mathrm{~S}$ gas. The corresponding response and recovery times were $97 \mathrm{~s}$ and $100 \mathrm{~s}$, respectively. The leaf-shaped $\mathrm{CuO}$ nanosheets-based gas sensor also exhibited excellent selectivity towards $\mathrm{H}_{2} \mathrm{~S}$ gas as compared to other analyte gases including $\mathrm{NH}_{3}, \mathrm{CH}_{3} \mathrm{OH}$, $\mathrm{CH}_{3} \mathrm{CH}_{2} \mathrm{OH}, \mathrm{CO}$ and $\mathrm{H}_{2}$. Finally, we have proposed a gas sensing mechanism based upon the formation of chemo-resistive $\mathrm{CuO}$ nanosheets.

Keywords: leaf-shaped; nanosheets; $\mathrm{CuO}$; gas sensor; $\mathrm{H}_{2} \mathrm{~S}$

\section{Introduction}

Recently, detecting hazardous substances and continuously monitoring the air pollutants, toxic gases and volatile organic gases have become the key to create a safe and healthy environment for society. Vehicular and other industrial activities are adding a variety of harmful toxic gases tremendously to the environment daily. Continuous exposure to such gases is the cause of serious health related problems in humans [1,2]. One such harmful gas is hydrogen sulfide $\left(\mathrm{H}_{2} \mathrm{~S}\right)$ which is highly corrosive, inflammable, and explosive, thus an extremely hazardous gas. Exposure to low concentrations of $\mathrm{H}_{2} \mathrm{~S}$ gas may cause a sore throat, coughing, skin itching, eye irritation and inflammation and irritation in the respiratory track, etc. $[3,4]$. In contrast, exposure to high concentrations (>100 ppm) may lead 
to olfactory nerve paralysis, loss of consciousness, myocardial damage and Alzheimer's disease. $\mathrm{H}_{2} \mathrm{~S}$ exposure above $300 \mathrm{ppm}$ may cause the sudden collapse of the cardiovascular system, damage to the human lungs and central nervous system [5-7].

A plethora of different analytical methods including conductometric [8], spectroscopic [9], micro-cantilever [10], gas chromatography [11], surface plasmon resonance [12], surface acoustic [13], field-emission transistors [14], microwave, [15] and chemo-resistive sensors based on nano-sized semiconductor metal oxides that have emerged as potential gas sensor materials and have been exhaustively investigated for variety of hazardous toxic gases $[16,17]$. Recently, many metals oxide-based gas sensors based on a chemo-resistive technique have been reported for $\mathrm{H}_{2} \mathrm{~S}$ gas sensing and monitoring. Qiao et al. [18] reported Mo-doped $\mathrm{BiVO}_{4}$ were with high sensitivity, selectivity, fast response towards $20 \mathrm{ppm}$ $\mathrm{H}_{2} \mathrm{~S}$ at optimized temperature of $150{ }^{\circ} \mathrm{C}$. Li et al. [19] analyzed the effect of integrating p-type and n-type semiconductor for $\mathrm{H}_{2} \mathrm{~S}$ by synthesizing metal-organic frameworksderived bamboo-like $\mathrm{CuO} / \mathrm{In}_{2} \mathrm{O}_{3}$ heterostructure. Flower-like structures composed of vertical aligned $\mathrm{ZnO}$ nanorods showed a high response and selectivity for $\mathrm{H}_{2} \mathrm{~S}$ at room temperature [20]. Hydrothermally synthesized pure $\mathrm{ZnO}$ and $\mathrm{Cu}$-doped $\mathrm{ZnO}$ nanostructures decorated with reduced graphene oxide were compared for their $\mathrm{H}_{2} \mathrm{~S}$ gas sensing behavior by Shewale et al. [21] and it was concluded that $\mathrm{Cu}$ doping and rGO inclusion, resulted in improved sensing parameters. $\mathrm{CuFe}_{2} \mathrm{O}_{4}$ nanoparticles prepared through sol-gel auto-combustion method, showed excellent sensitivity towards $25 \mathrm{ppm} \mathrm{H}_{2} \mathrm{~S}$ at $80{ }^{\circ} \mathrm{C}$ [22].

Among the various chemo-resistive metal oxides, cupric oxide $(\mathrm{CuO})$ poses interesting properties like a p-type semiconducting nature, a narrow band gap (1.2 eV in bulk), high charge carrier concentrations, superior physical and chemical properties, ease of synthesis, versatile morphologies controlled through reaction conditions, reagent concentration and selectivity of synthetic method [23,24]. CuO nano/microstructures such as flower-shaped [25], nanoneedles [26], nanorods [27], nanowires [28], and nanosheets [29] have been synthesized utilizing hydrothermal, sol-gel, coprecipitation, electrospinning techniques. Owing to these versatile features, $\mathrm{CuO}$ nanostructures have been explored for numerous highly toxic volatile organic compounds and gases like ammonia [30], acetone [31], alcohols [32], liquified petroleum gas [33], carbon monoxide [34], sulphur dioxide [35], nitrogen dioxide [36] and many more. A detailed literature survey revealed that the two-dimensional $\mathrm{CuO}$ nanomaterials are rarely reported for the sensing of $\mathrm{H}_{2} \mathrm{~S}$ gas.

Herein, we are reporting a simple, economic and low temperature synthesis of leafshaped $\mathrm{CuO}$ nanosheets. As-synthesized $\mathrm{CuO}$ was examined through different techniques to confirm its formation, purity, crystal phase, morphology, vibrational, optical and diffraction features. A chemo-resistive type gas sensor based on leaf-shaped $\mathrm{CuO}$ nanosheets was fabricated to effectively and selectively detect $\mathrm{H}_{2} \mathrm{~S}$ gas. The sensor parameters were analyzed under varying degree of the operating temperatures and concentrations. Finally, a gas sensing mechanism was also proposed.

\section{Materials and Methods}

\subsection{Synthesis of Leaf-Shaped $\mathrm{CuO}$ Nanosheets}

Leaf-shaped $\mathrm{CuO}$ nanosheets were grown by a low temperature solution process. In a typical synthesis, $2 \mathrm{mmol}$ of Copper (II) nitrate trihydrate $\left(\mathrm{Cu}\left(\mathrm{NO}_{3}\right)_{2} \cdot 3 \mathrm{H}_{2} \mathrm{O}\right)$ was first dissolved in $50 \mathrm{~mL}$ of deionized (DI) water under vigorous stirring for $1 \mathrm{~h}$. Separately $10 \mathrm{mmoL}$ sodium hydroxide $(\mathrm{NaOH})$ was freshly prepared in $20 \mathrm{~mL}$ DI water. Then $\mathrm{NaOH}$ solution was introduced to the $\mathrm{Cu}$ precursor solution under stirring until the $\mathrm{pH}$ of solution was reached to 11. Afterward, the reaction mixture was put into scotch Durant bottle and strongly tight the cover of the bottle. The Scotch Durant bottle was placed in an oven and maintained the temperature at $70{ }^{\circ} \mathrm{C}$ for $24 \mathrm{~h}$. After completion of the reaction, the precipitate was washed several times with distilled water and ethanol repeatedly to remove the complexes and other impurities. Lastly, the desired product was dried at $80{ }^{\circ} \mathrm{C}$ to obtain $\mathrm{CuO}$ powder. Figure 1 depicts the typical schematic for the synthesis of leaf-shaped $\mathrm{CuO}$ nanosheets. 


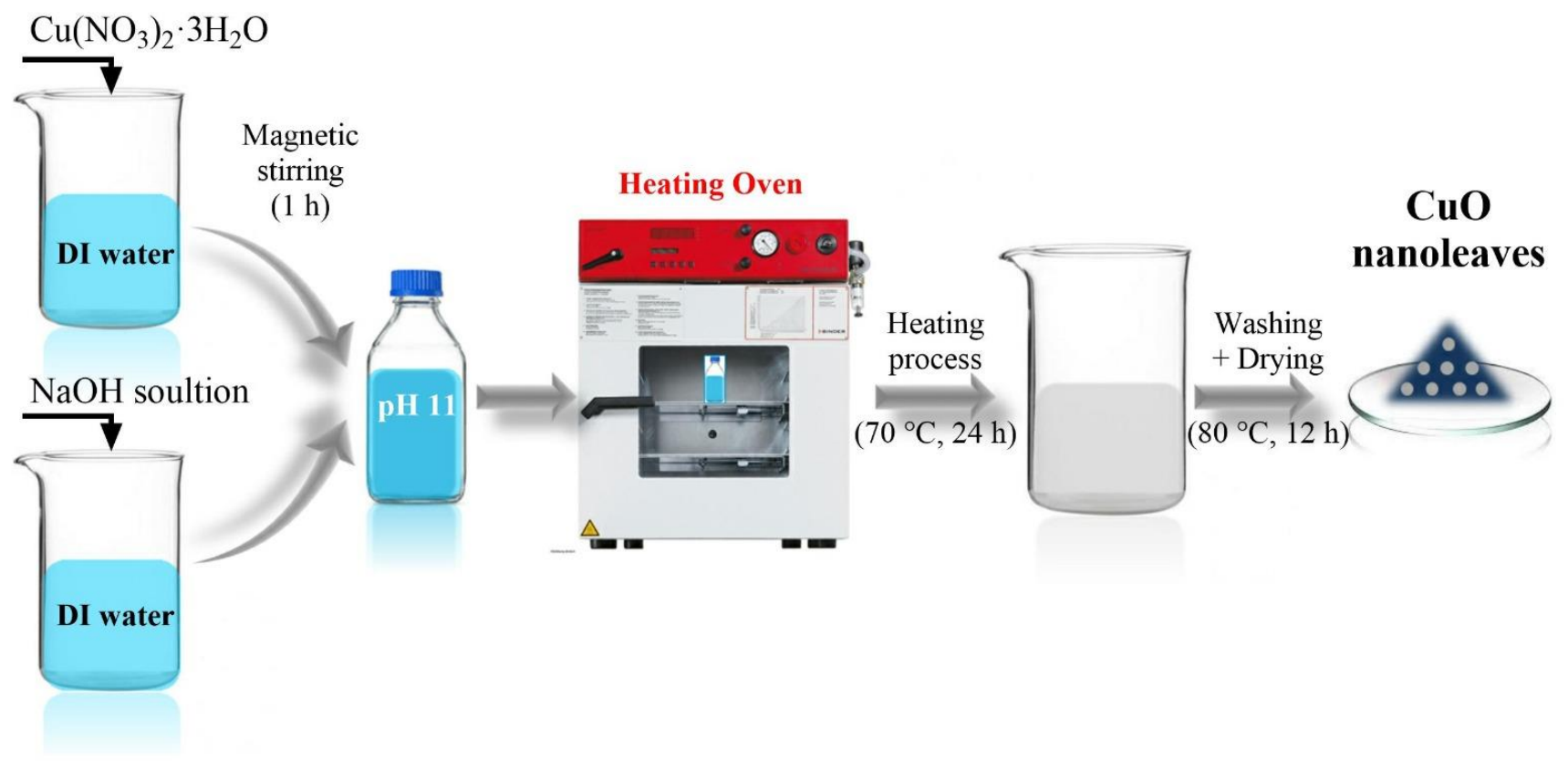

Figure 1. Schematic to synthesize leaf-shaped $\mathrm{CuO}$ nanosheets.

\subsection{Characterization of Leaf-Shaped $\mathrm{CuO}$ Nanosheets}

Field emission scanning electron microscopy (FESEM, JEOL-JSM-7600F, Boston, MA, USA) associated with energy dispersive spectroscopy (EDS) and transmission electron microscopy (TEM, JEOL-JEM-2100F; Boston, MA, USA) associated with high-resolution TEM (HRTEM) were utilized to examine the detailed structural, elemental, compositional, and morphological features of the hydrothermally synthesized leaf-shaped CuO nanosheets. X-ray diffractometer (XRD, PANanalytical Xpert Pro., Davis, CA, USA) studies were performed using $\mathrm{Cu}-\mathrm{K} \alpha$ radiation $(\lambda=1.542 \AA)$ for analyzing the crystal phases and size for the synthesized $\mathrm{CuO}$. Fourier transform infrared spectroscopic (FTIR, Perkin Elmer-FTIR Spectrum-100; Markham, ON, Canada ) technique, through KBr palletization, along with Raman spectroscopy (Perkin Elmer-Raman Station-400 series, Markham, ON, Canada) were used to study the vibrational properties. The photoluminescence spectra (PL) were analyzed by the FP-6500 (JASCO, Easton, MD, USA) fluorometer using CuO suspension in ethanol solvent.

\subsection{Fabrication of $\mathrm{H}_{2} \mathrm{~S}$ Gas Sensor Based on Leaf-Shaped $\mathrm{CuO}$ Nanosheets}

A slurry was made, by mixing leaf-shaped $\mathrm{CuO}$ nanosheets with diethanolamine and ethanol, and coated on the surfaces of ceramic tube to obtain thick films. The gas sensing characteristics were examined by computer-controlled gas sensing analysis system. The details of the gas sensing system are presented elsewhere [16]. The test chamber volume is $4 \mathrm{~L}$. During the sensing measurements, the heating system adjusts the temperature directly. When the resistance of the sensors became stable, the dynamic gas distribution system injected the target gas into the chamber. The sensors' resistance then changed, and the test chamber was opened when the resistance returned to normal, and the gas sensors would recover to origin states. The gas sensor response was defined as the ratio of device resistance in the presence of testing gas $\left(R_{g}\right)$ and in air $\left(R_{a}\right)$ at the same temperature (Equation (1)).

$$
\text { Gas response }=\frac{\mathrm{R}_{\mathrm{g}}}{\mathrm{R}_{\mathrm{a}}}
$$




\section{Results and Discussion}

\subsection{Characterizations}

The surface features, morphology and microstructure of the as-synthesized $\mathrm{CuO}$ nanosheets were characterized by a field emission scanning electron microscope (FESEM) at resolution scales of $5 \mu \mathrm{m}$ (Figure 2a), $2 \mu \mathrm{m}$ (Figure 2b), $1 \mu \mathrm{m}$ (Figure 2c) and $500 \mathrm{~nm}$ (Figure 2d). All FESEM images revealed a thin leaf-like morphology for $\mathrm{CuO}$ nanosheets. The surfaces of the nanosheets were very smooth but the edges displayed small fringes, features similar to plant leaves. The average width of the leaf-shaped nanosheets was $\sim 250 \mathrm{~nm}$. However, the length-wise dimensions were quite variable.

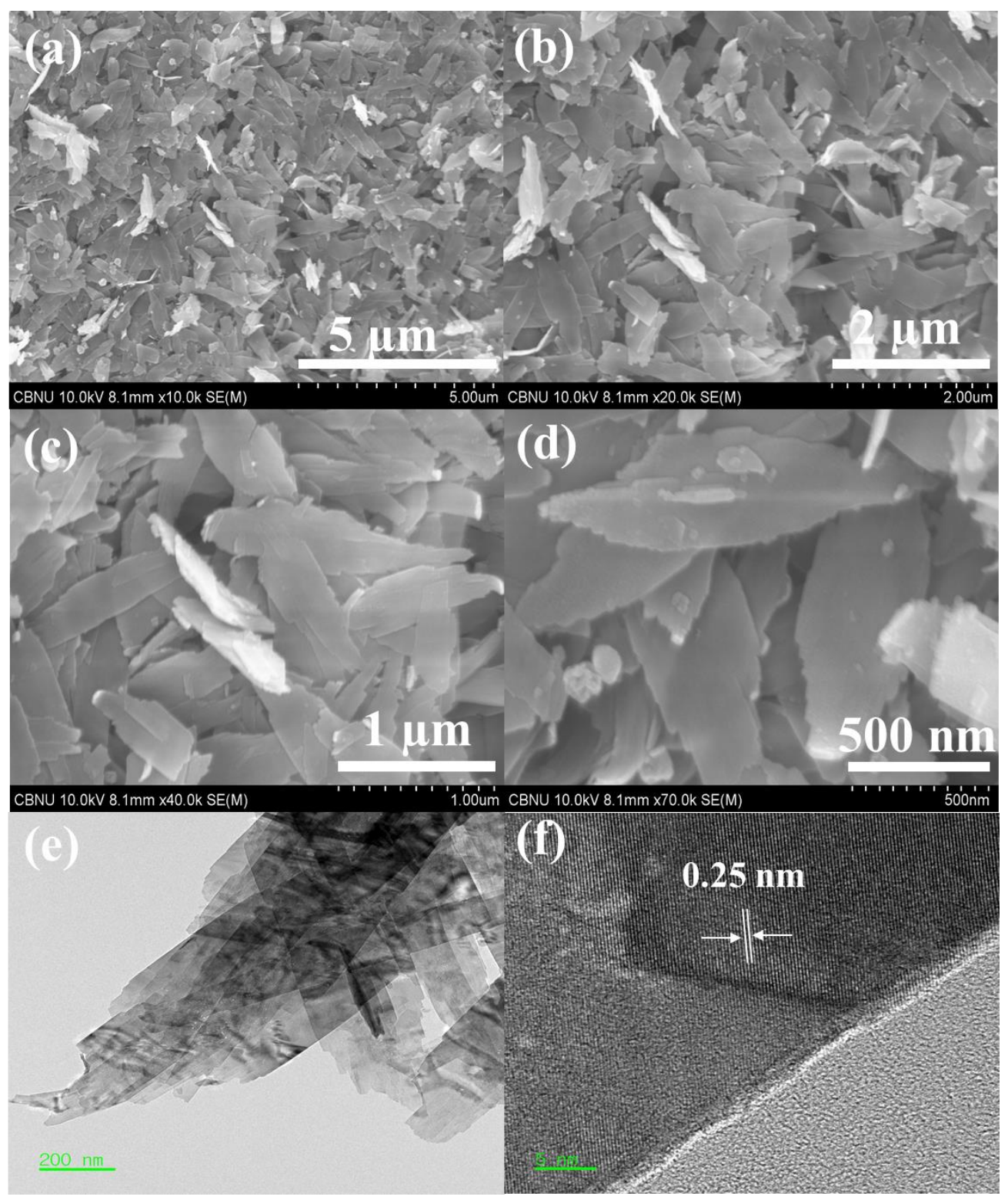

Figure 2. (a,b) Low-magnification, (c,d) high-resolution FESEM images, (e) TEM image and (f) high-resolution TEM image of hydrothermally synthesized leaf-shaped $\mathrm{CuO}$ nanosheets.

More details of the microstructural properties of $\mathrm{CuO}$ nanoleaves were further explored through transmission electron microscopy (TEM; JEOL-JEM-2100F) equipped with high-resolution TEM (HRTEM). In Figure 2e,f the typical TEM and HRTEM images of a leaf-shaped $\mathrm{CuO}$ nano-sheet, respectively are shown. Thin leaf like morphologies of the $\mathrm{CuO}$ nanosheets, as examined through FESEM images, were confirmed by the TEM image 
(Figure 2e). Similar to the reported literature, the interplanar distance of $\sim 0.25 \mathrm{~nm}$ which corresponds to the (1 110$)$ diffraction plane of the monoclinic phase of the $\mathrm{CuO}$ was from the HRTEM images (Figure 2f).

The crystalline phase of hydrothermally synthesized $\mathrm{CuO}$ leaf-shaped nanosheets was analyzed by XRD as shown in Figure 3. Well defined diffraction patterns at $2 \theta$ values $32.45^{\circ}, 35.45^{\circ}, 38.65^{\circ}, 46.25^{\circ}, 48.75^{\circ}, 53.50^{\circ}, 58.25^{\circ}, 61.50^{\circ}, 66.25^{\circ}$ and $68.00^{\circ}$ are due to the

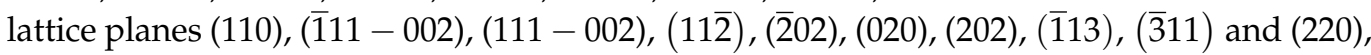
respectively. These diffraction peaks and planes are the characteristics of the monoclinic tenorite crystalline phase of the $\mathrm{CuO}$. The data is well-matched with the JCPDS 48-1548 card as well as the reported literature. Absence of peaks related to any other crystalline phase and impurity further indicate the successful synthesis of highly pure monophasic $\mathrm{CuO}$ nanoleaves via facile hydrothermal process.

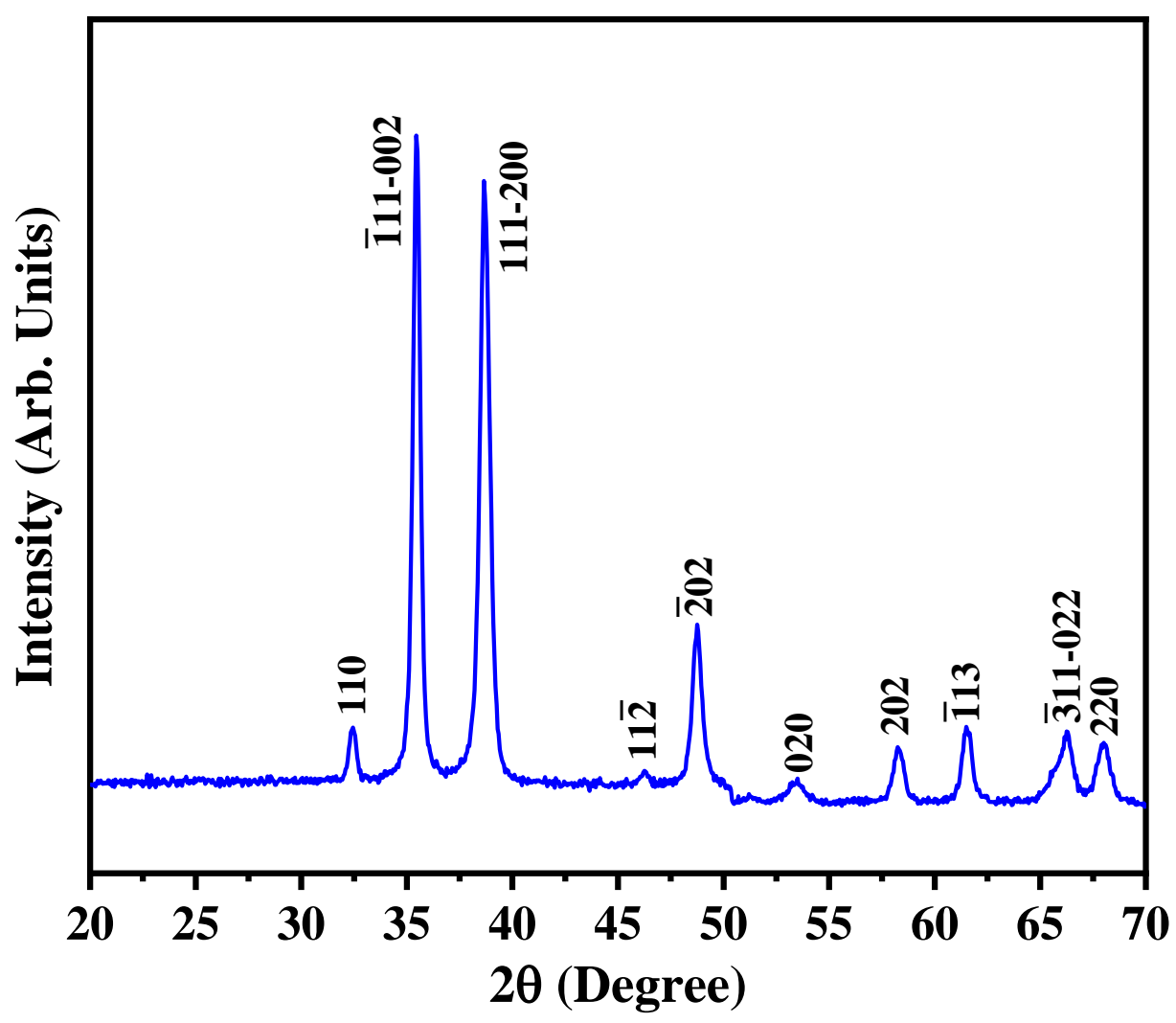

Figure 3. XRD patterns of hydrothermally synthesized leaf-shaped $\mathrm{CuO}$ nanosheets.

The crystal size (d) of the leaf-shaped $\mathrm{CuO}$ with monoclinic crystalline phase was determined by using Debye-Scherrer equation (Equation (2)).

$$
\mathrm{d}=\frac{\mathrm{K} \lambda}{\beta \cos \theta}
$$

where $\mathrm{K}$ is a numerical factor (In this case $\mathrm{K}=0.89$ ), $\beta$ is full width at half maximum (FWHM) and $\lambda$ is $0.154 \mathrm{~nm}$. Some of the most intense XRD peaks, as mentioned in Table 1 were used to calculate the FWHM. The average crystallite size for leaf-shaped $\mathrm{CuO}$ nanosheets was found to be $14.28 \mathrm{~nm}$. 
Table 1. Diffraction parameters for leaf-shaped $\mathrm{CuO}$ nanosheets.

\begin{tabular}{cccc}
\hline Diffraction Planes $(\boldsymbol{h k l})$ & Diffraction Angles $\left(^{\circ}\right)$ & FWHM $(\boldsymbol{\beta})$ & The Crystallite Size $(\mathbf{n m})$ \\
\hline$\left(\begin{array}{c}1 \\
1\end{array}\right)$ & 32.45 & 0.7597 & 10.78 \\
$(\overline{1} 11-0$ ) $)$ & 35.45 & 0.4275 & 19.31 \\
$(111-200)$ & 38.65 & 0.5713 & 14.58 \\
$(\overline{2} 02)$ & 48.75 & 0.6051 & 14.26 \\
$(202)$ & 58.25 & 0.7340 & 12.26 \\
$(\overline{1} 13)$ & 61.50 & 0.6320 & 14.48 \\
\hline
\end{tabular}

Since, for gas sensing applications, the composition and the purity of the gas sensor electrode material is of utmost importance, the as-synthesized leaf-shaped $\mathrm{CuO}$ nanosheets were subjected to elemental composition analysis using EDS attached with the FESEM. Figure $4 \mathrm{a}$ is representing the EDS spectrum of the leaf-shaped $\mathrm{CuO}$ nanosheets which shows only the spectral peaks for copper and oxygen elements. This ensured that the $\mathrm{CuO}$ nanosheets are free of any impurities.
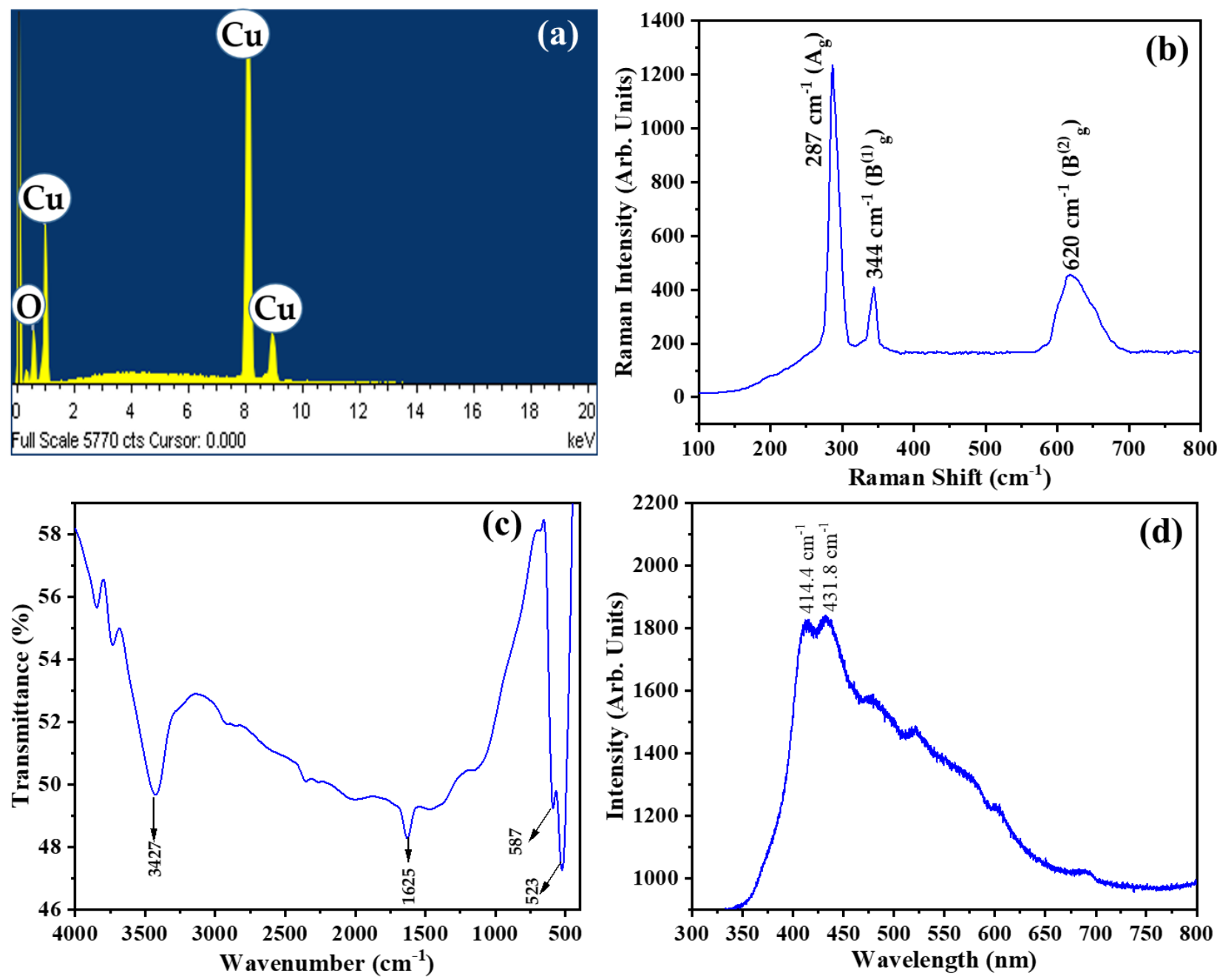

Figure 4. (a) Typical EDS spectrum, (b) Raman spectrum, (c) FTIR spectrum and (d) Photoluminescence spectra of leaf-shaped $\mathrm{CuO}$ nanosheets.

Structural fingerprinting through Raman spectroscopy is an important qualitative technique to analyze the composition, vibrational and scattering properties of the metal oxide semiconductors [37]. The primitive cell for the monoclinic tenorite crystalline phase of $\mathrm{CuO}$ consists of two molecules per unit cell with the space group $C_{2 h}^{6}$ [29]. In general, there are 
nine zone-center optical phonon modes for $\mathrm{CuO}$ with symmetries $4 \mathrm{~A}_{\mathrm{u}}+5 \mathrm{~B}_{\mathrm{u}}+\mathrm{A}_{\mathrm{g}}+2 \mathrm{~B}_{\mathrm{g}}$. However, out of these modes only three phonon modes with symmetries $A_{g}$ and $2 B_{g}$ are Raman active [38]. The typical Raman spectrum for leaf-shaped $\mathrm{CuO}$ nanosheets consist of three distinct characteristic Raman peaks at 287, 344 and $620 \mathrm{~cm}^{-1}$ (Figure $4 \mathrm{~b}$ ). The distinct sharp peak at $287 \mathrm{~cm}^{-1}$ is attributed to $\mathrm{A}_{\mathrm{g}}$ phonon mode, whereas less intense Raman peaks at 344 and $620 \mathrm{~cm}^{-1}$ are assigned to $\mathrm{Bg}_{\mathrm{g}}{ }^{1}$ and $\mathrm{Bg}_{\mathrm{g}}{ }^{2}$ modes, respectively. The peaks are in good agreement with the Raman peaks reported for urchin like $\mathrm{CuO}$ hollow microspheres [39], $\mathrm{CuO}$ nanoplates [40] and $\mathrm{CuO}$ nanoparticles [41].

Figure $4 \mathrm{c}$ is representing the well-defined FTIR spectrum for the hydrothermally synthesized $\mathrm{CuO}$ nanosheets. FTIR peaks appeared at 523,587, 1625 and $3427 \mathrm{~cm}^{-1}$ for leaf-shaped $\mathrm{CuO}$ nanosheets. Very sharp vibrational peaks in the fingerprint region i.e., at 523 and $587 \mathrm{~cm}^{-1}$ may be assigned to the stretching vibrations of the M-O bonds (In this case $\mathrm{Cu}-\mathrm{O}$ bond) [42]. Additional peaks at $1625 \mathrm{~cm}^{-1}$ and a wide FTIR band at $3427 \mathrm{~cm}^{-1}$ may be attributed to the bending and stretching vibrations, respectively for the $\mathrm{O}-\mathrm{H}$ groups of physiosorbed $\mathrm{H}_{2} \mathrm{O}$ molecules on the surface of the leaf-shaped $\mathrm{CuO}$ nanosheets [43].

Photoluminescence (PL) spectroscopy is usually helpful in predicting the charge carrier trapping efficiencies, surface defects as well as the recombination of the $\mathrm{e}^{-} / \mathrm{h}^{+}$pairs in a semiconductor metal oxide. PL spectrum of the leaf-shaped $\mathrm{CuO}$ nanosheets showed typical green emission within the wavelength range of 400-450 nm (Figure 4d). The broad nature of the PL spectrum further indicates the presence of the surface defects on $\mathrm{CuO}$ nanosheets [44]. Emission peaks at 414.4 and $431.8 \mathrm{~nm}$ are supposed to arises from the ionized oxygen vacancies resulting in green emission from the surface of the leaf-shaped $\mathrm{CuO}$ nanosheets [45]. The band gap for $\mathrm{CuO}$ was calculated from the emission peaks at 414.4 and $431.8 \mathrm{~nm}$ using well-known Planck's equation (Equation (3)). The calculated band gap was in the range $2.99-2.87 \mathrm{eV}$ which is close to the reported value [45].

$$
\mathrm{E}_{\mathrm{g}}=\frac{\mathrm{hc}}{\lambda_{\max }}
$$

\section{2. $\mathrm{H}_{2} \mathrm{~S}$ Gas Sensing Applications of $\mathrm{CuO}$ Nanosheets}

Semiconductor metal oxides are the key component of the most of the recently studied gas sensors due to their low-cost synthesis, biocompatibility, ease of sensor fabrication and excellent gas sensing behavior. Gas sensing parameters of such sensors are controlled by different factors like operating temperature, gas concentration, composition of the sensor material, surface modifications, crystal size, and most importantly the nature of the gas which significantly contributes to the selectivity of the sensor.

One of the most important controlling factors is the operating temperature since it controls the adsorption $\rightleftharpoons$ desorption equilibrium of the gas and $\mathrm{O}_{2}$ molecules, kinetics of the redox reactions, and concentration of oxygen vacancies on the surface of the sensor materials. Herein, the optimized temperature was found to be $300{ }^{\circ} \mathrm{C}$ for the sensing of 200 ppm $\mathrm{H}_{2} \mathrm{~S}$ gas through leaf-shaped $\mathrm{CuO}$ nanosheets based gas sensor device. The corresponding gas response was 35.3 at optimized temperature. Low sensor response below $300{ }^{\circ} \mathrm{C}$ is due to insufficiently activation of the $\mathrm{H}_{2} \mathrm{~S}$ gas molecules to react with the surface adsorbed $\mathrm{O}_{2}$ molecules (Figure 5a). As the temperature is increased more $\mathrm{O}_{2}$ molecules are reduced to the oxygenated anionic species which further react with $\mathrm{H}_{2} \mathrm{~S}$ molecules, thereby increasing gas response. However, beyond optimized temperature, the increased rate of the desorption of the $\mathrm{H}_{2} \mathrm{~S}$ and $\mathrm{O}_{2}$ molecules decreases the gas response. 

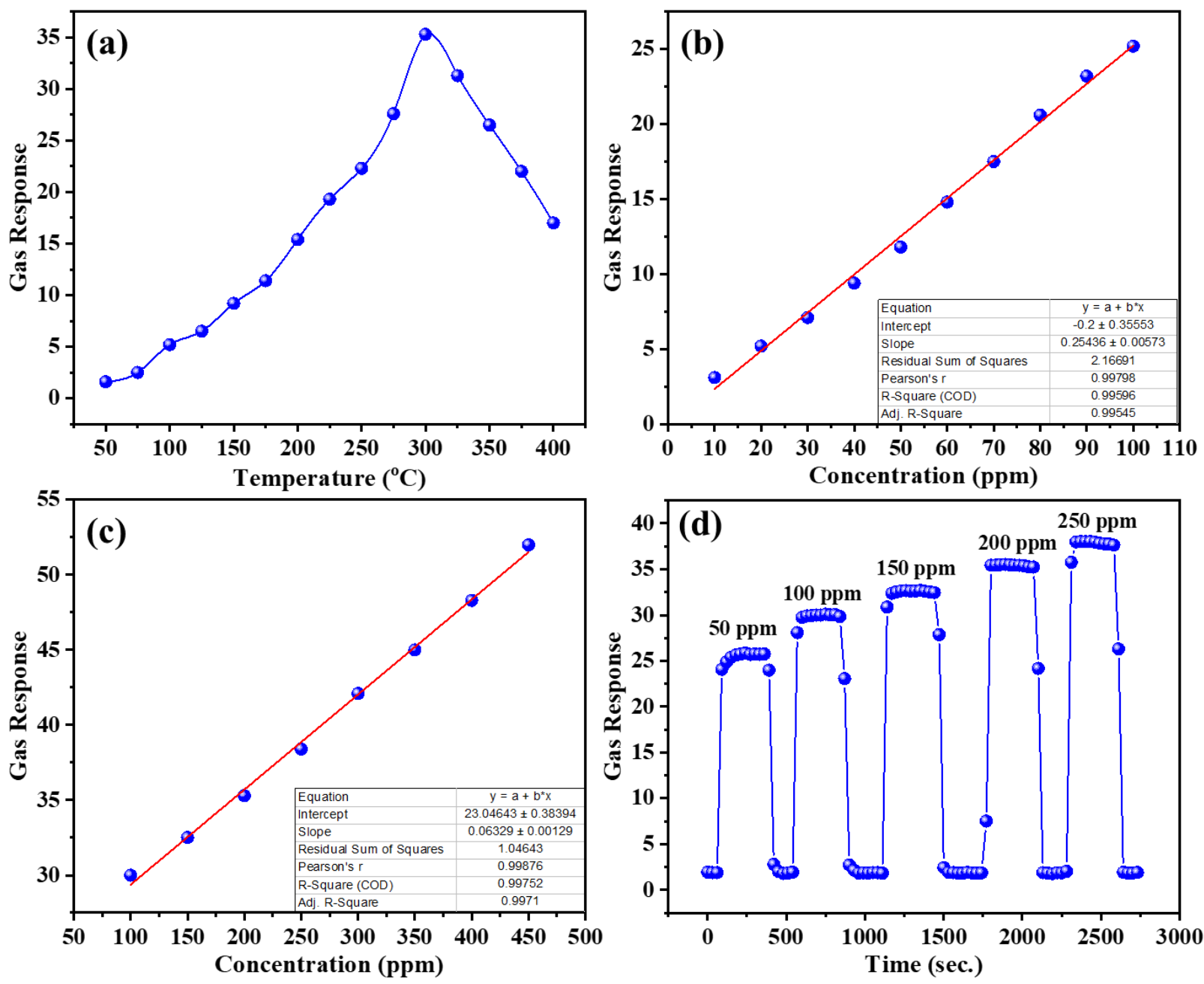

Figure 5. (a) Gas sensor response to $200 \mathrm{ppm}_{2} \mathrm{~S}$ gas as a function of the operating temperature, (b,c) dependency of gas sensor response on low and high concentration, respectively for $\mathrm{H}_{2} \mathrm{~S}$ gas at optimized temperature and (d) Dynamic response plots for leaf-shaped $\mathrm{CuO}$ nanosheets based $\mathrm{H}_{2} \mathrm{~S}$ gas sensor.

The gas sensor response depends upon the rate of the redox reactions occurring at the surface of the sensor material, which in turn is directly proportional to the concentration of the analyte gas. Therefore, the gas responses of the leaf-shaped $\mathrm{CuO}$ nanosheets based gas sensor for low concentrations (10-100 ppm) (Figure 5b) as well as high concentrations (100-450 ppm) (Figure 5c) of the $\mathrm{H}_{2} \mathrm{~S}$ gas, at an optimized temperature of $300{ }^{\circ} \mathrm{C}$, were recorded. Excellent linearities were observed between the gas response and $\mathrm{H}_{2} \mathrm{~S}$ concentration with determinant coefficients of 0.99545 and 0.99710 for low and high concentration ranges, respectively. The real time dynamic response-recovery curves for the fabricated sensor against different concentrations of the $\mathrm{H}_{2} \mathrm{~S}$ gas ranging from $50-250 \mathrm{ppm}$ at $300{ }^{\circ} \mathrm{C}$ are shown in Figure 5d. The gas response steeply increased in the presence of the analyte gas and as soon as the supply of the gas was interrupted, the gas response returned to the original baseline value. The behavior was observed for all the chosen $\mathrm{H}_{2} \mathrm{~S}$ concentrations at optimum temperature. Excellent gas response can be attributed to the unique nanosheet like morphology for of $\mathrm{CuO}$ which provide a large specific surface area for the high extent of adsorption of $\mathrm{O}_{2}$ and $\mathrm{H}_{2} \mathrm{~S}$ gas molecules.

The repeatability and reusability aspects of the $\mathrm{CuO}$ nanosheets based sensor towards sequential exposure of $200 \mathrm{ppm} \mathrm{H}_{2} \mathrm{~S}$ gas at optimized temperature of $300^{\circ} \mathrm{C}$ were examined by analyzing gas responses for successive twelve cycles. The outcomes of the analysis are shown in Figure 6a. Perfectly matched gas responses for each cycle indicate excellent response reproducibility of the fabricated $\mathrm{H}_{2} \mathrm{~S}$ gas sensors. The response and recovery 
times are also two important factors in the gas sensor applications. The response $\left(\tau_{\text {res }}\right)$ and recovery time $\left(\tau_{\text {rec }}\right)$ relate to the time required by the sensor to attain the $90 \%$ steady response value and the time required to reach $10 \%$ of the initial gas response, respectively [35]. Figure $6 \mathrm{~b}$ shows the response and recovery curves for leaf-shaped $\mathrm{CuO}$ nanosheets based gas sensor towards $200 \mathrm{ppm}$ of $\mathrm{H}_{2} \mathrm{~S}$ gas at optimized temperature. Response and recovery times were $97 \mathrm{~s}$ and $100 \mathrm{~s}$, respectively.
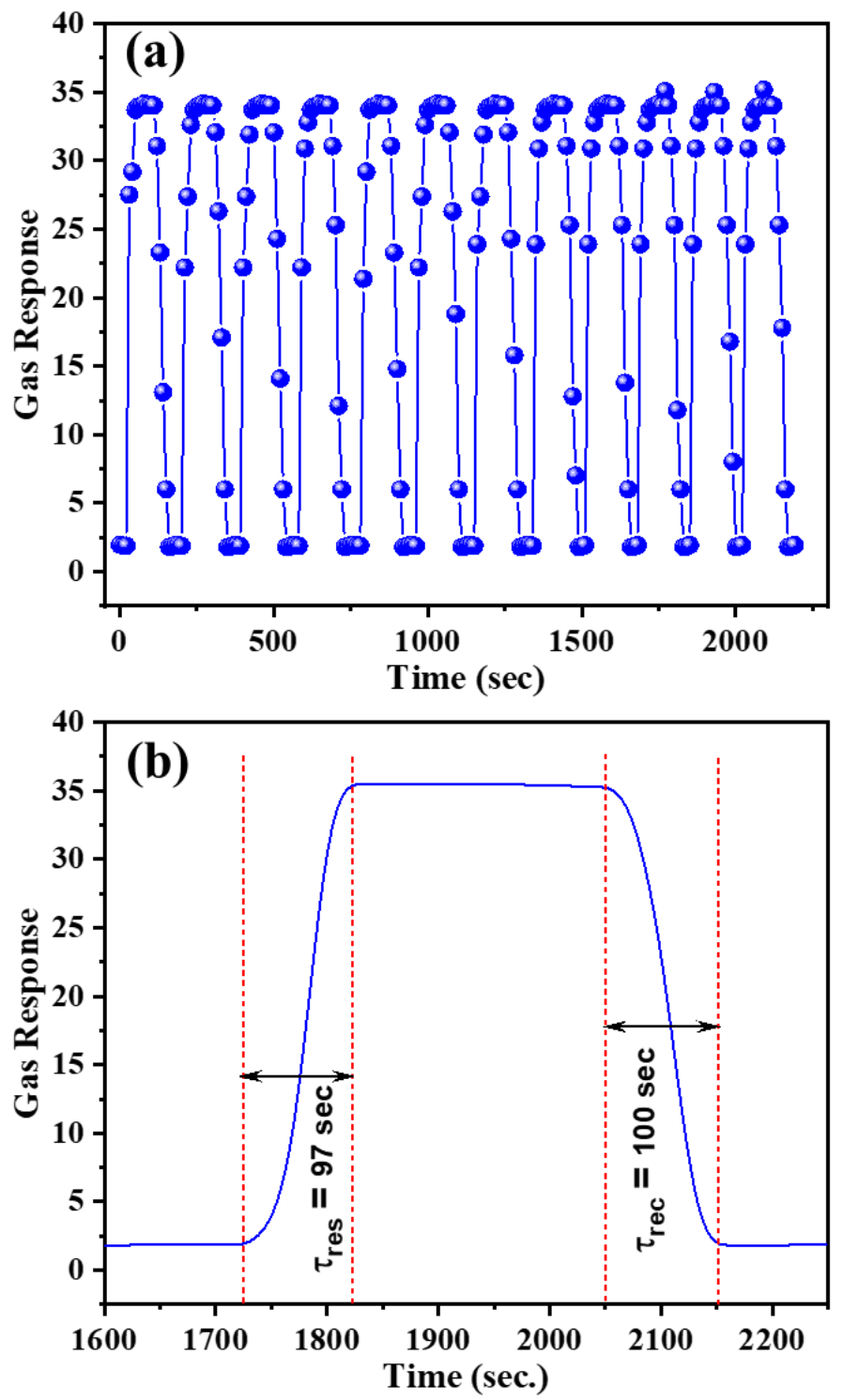

Figure 6. (a) Reproducibility study and (b) Response curve for the calculation of response and recovery times.

Inspired by the excellent gas sensing behavior of the as-fabricated gas sensor, the selectivity test was also performed (Figure 7). The test shows that the leaf-shaped $\mathrm{CuO}$ nanosheets based gas sensor was more selective towards $\mathrm{H}_{2} \mathrm{~S}$ gas as compared to other analyte gases including $\mathrm{NH}_{3}, \mathrm{CH}_{3} \mathrm{OH}, \mathrm{CH}_{3} \mathrm{CH}_{2} \mathrm{OH}, \mathrm{CO}$ and $\mathrm{H}_{2}$. For 200 ppm concentrations, the gas responses towards $\mathrm{H}_{2} \mathrm{~S}$ observed were 4.84, 3.21, 2.94, 5.19 and 6.30 times higher than $\mathrm{NH}_{3}, \mathrm{CH}_{3} \mathrm{OH}, \mathrm{CH}_{3} \mathrm{CH}_{2} \mathrm{OH}, \mathrm{CO}$ and $\mathrm{H}_{2}$, respectively at $300{ }^{\circ} \mathrm{C}$ temperature. 


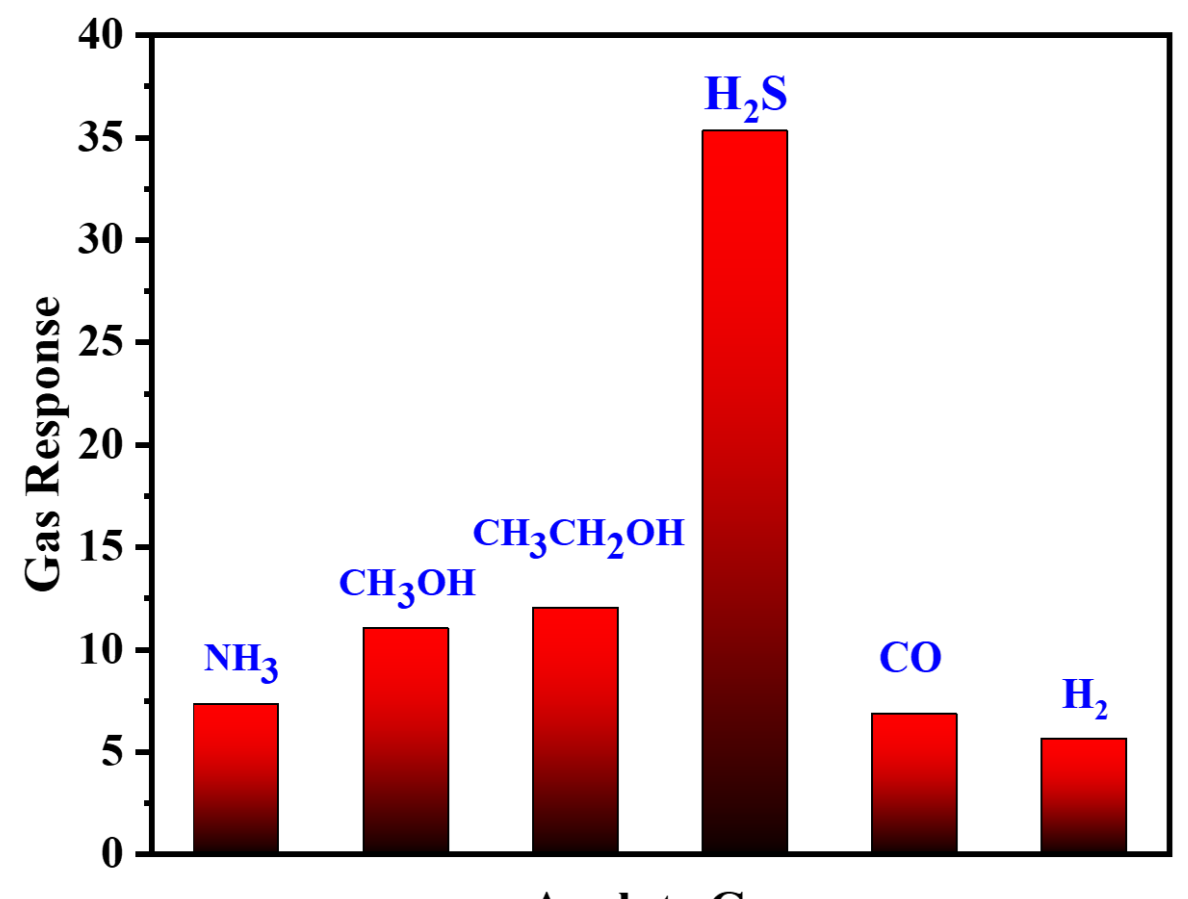

Analyte Gas

Figure 7. Selectivity studies of the leaf-shaped $\mathrm{CuO}$ nanosheets based $\mathrm{H}_{2} \mathrm{~S}$ gas sensor.

\subsection{Proposed Gas Sensing Mechanism}

Since $\mathrm{CuO}$ is a typical p-type semiconductor metal oxide, its gas-sensing behavior is attributed to the change in the resistance resulted due to redox reactions occurring on its surface between the $\mathrm{H}_{2} \mathrm{~S}$ gas molecules and various oxygenated anionic species. The resistance changes are also resulted by the adsorption $\rightleftharpoons$ desorption equilibrium of the analyte gases as a function of temperature and the concentration. In the presence of air ambient conditions, p-type $\mathrm{CuO}$ semiconductor ionizes adsorbed $\mathrm{O}_{2}$ molecules into various anionic species including $\mathrm{O}_{2}^{-}, \mathrm{O}_{2}^{2-}, \mathrm{O}^{2-}$ and $\mathrm{O}^{-}$at optimized temperature conditions utilizing the conduction band electrons (Equations (4)-(6)). This loss of electrons from the conduction band forms a positively charged hole accumulation layer.

$$
\begin{gathered}
\mathrm{O}_{2}(g) \rightarrow \mathrm{O}_{2}(\text { ads }) \\
\mathrm{O}_{2(g)} \stackrel{e_{C B}^{-}}{\rightarrow} \mathrm{O}_{2(\text { ads })}^{-} \stackrel{e_{C B}^{-}}{\rightarrow} \mathrm{O}_{2(\text { ads })}^{2-} \\
\mathrm{O}_{2(g)} \stackrel{e_{C B}^{-}}{\rightarrow} 2 \mathrm{O}_{(\text {ads })}^{-} \stackrel{e_{C B}^{-}}{\rightarrow} 2 \mathrm{O}_{(\text {ads })}^{2-}
\end{gathered}
$$

Due to the formation of positively charged hole accumulation layer near the surface of the $\mathrm{CuO}$ nanosheets which stimulates a competitive resistance between the highly insulating resistive core and the hole accumulation layer [29].

The oxidation of the $\mathrm{H}_{2} \mathrm{~S}$ to $\mathrm{SO}_{2}$ and $\mathrm{H}_{2} \mathrm{O}$ on the surface of the leaf-shaped $\mathrm{CuO}$ nanosheet results in the release of the electrons which are trapped by the positively charged holes resulting in electron-hole recombination (Equations (7)-(9)). The thickness of the hole depletion layer is decreased which subsequently enhances the resistance of the leaf-shaped $\mathrm{CuO}$ nanosheets [46] (Figure 8).

$$
\begin{aligned}
\mathrm{H}_{2} \mathrm{~S}+3 \mathrm{O}_{(\text {Adsorbed })}^{-} & \rightarrow \mathrm{SO}_{2}+\mathrm{H}_{2} \mathrm{O}+3 e^{-} \\
\mathrm{H}_{2} \mathrm{~S}+3 \mathrm{O}_{(\text {Adsorbed })}^{2-} & \rightarrow \mathrm{SO}_{2}+\mathrm{H}_{2} \mathrm{O}+6 e^{-} \\
e^{-}+h^{+} & \rightarrow \mathrm{Null}
\end{aligned}
$$




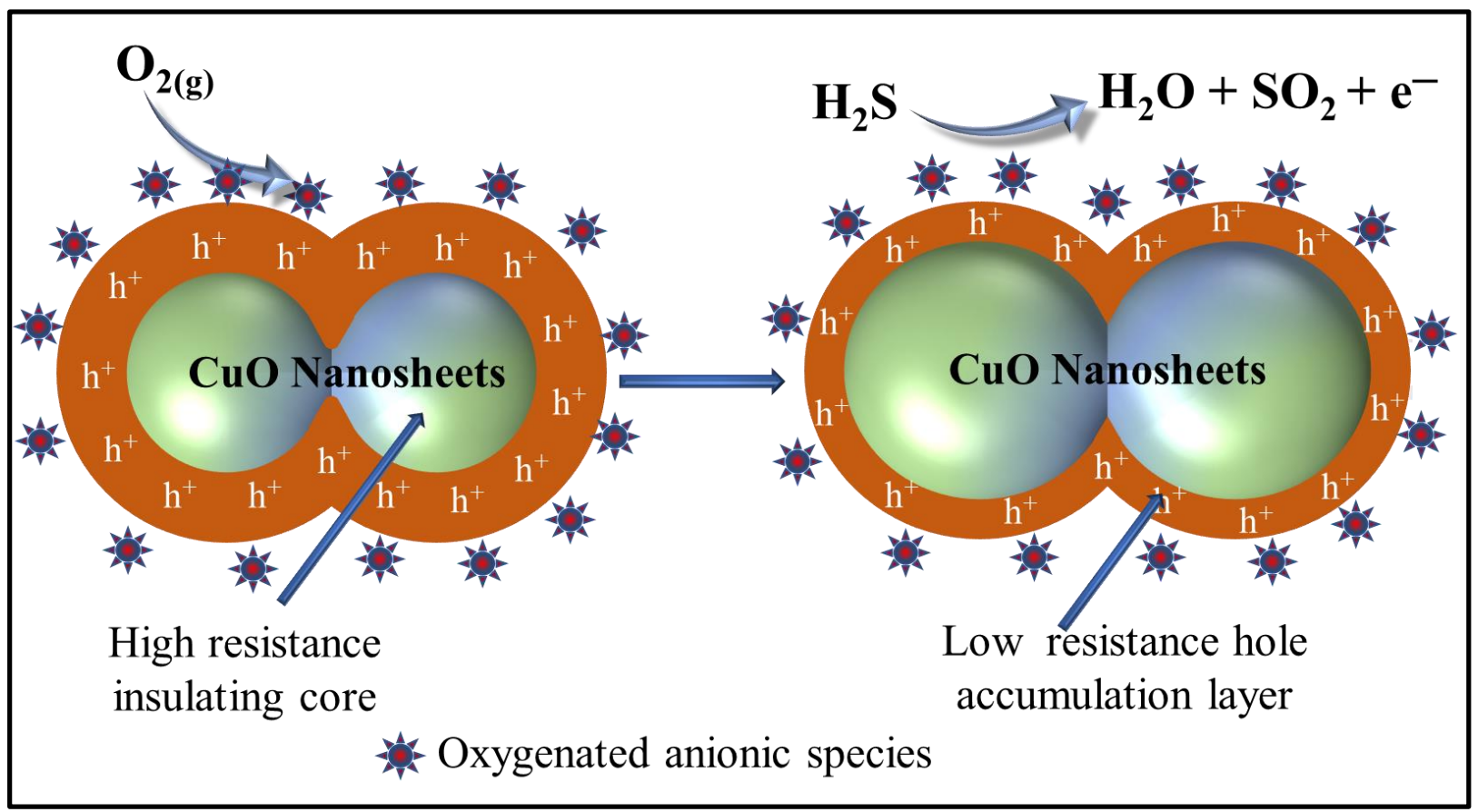

Figure 8. Schematics of the $\mathrm{H}_{2} \mathrm{~S}$ gas sensing mechanism by leaf-shaped $\mathrm{CuO}$ nanosheets.

In order to further justify the novelty of the present work, a comparative analysis of the gas sensor parameters of the present study is shown in Table 2 and compared to other reported $\mathrm{CuO}$ nanostructures. From the Table 2, it can be inferred that as-synthesized leaf-shaped $\mathrm{CuO}$ nanosheets show the better gas sensing performance as compared to reported pure $\mathrm{CuO}$ nanostructures and composites of $\mathrm{CuO}$.

Table 2. Sensing parameters for various $\mathrm{CuO}$ gas sensor materials towards $\mathrm{H}_{2} \mathrm{~S}$ gas.

\begin{tabular}{|c|c|c|c|c|c|c|}
\hline Sensor Material & Conc. & $\begin{array}{c}\text { Gas } \\
\text { Response }\end{array}$ & Response Time (s) & Recovery Time (s) & $\mathrm{T}\left({ }^{\circ} \mathrm{C}\right)$ & Ref. \\
\hline $\mathrm{CuO}$ nanosheets & $2 \mathrm{ppb}$ & $320 *$ & 4 & 9 & 240 & [47] \\
\hline Porous $\mathrm{CuO}$ nanosheet & $10 \mathrm{ppb}$ & $1.25^{\#}$ & 234 & 76 & RT & [48] \\
\hline rGO/CuO nanofibers & $10 \mathrm{ppm}$ & $11.7^{\$}$ & - & - & 300 & [49] \\
\hline Hierarchically flower-like $\mathrm{CuO}$ & 1 ppm & $2.1^{\$}$ & 240 & 1341 & RT & [50] \\
\hline $\mathrm{CuO}-\mathrm{ZnO}$ hollow spheres & 5 ppm & $13.3^{\#}$ & 270 & 720 & 336 & {$[51]$} \\
\hline $\begin{array}{c}\text { Hierarchical } \mathrm{CuO} / \mathrm{NiO} \\
\text { nanowall arrays }\end{array}$ & 5 ppm & $36.9^{\$}$ & - & 13 & 133 & [52] \\
\hline $\mathrm{CuO} / \mathrm{MoS}_{2}$ film & $30 \mathrm{ppm}$ & $61 *$ & 26 & 11 & RT & {$[53]$} \\
\hline $\mathrm{CuO}$ nanosheet monolayer & 200 & $350 *$ & 20 & 120 & 250 & [54] \\
\hline Leaf-shaped $\mathrm{CuO}$ nanosheets & 200 & $35.3^{\$}$ & 97 & 100 & 300 & This work \\
\hline
\end{tabular}

\section{Conclusions}

In summary, leaf-shaped $\mathrm{CuO}$ nanosheets were prepared through facile low temperature hydrothermal process and were subsequently characterized. The average width of the leaf-shaped nanosheets was $250 \mathrm{~nm}$ and the surface were smooth but the edges displayed small fringes. The $\mathrm{H}_{2} \mathrm{~S}$ gas sensor was fabricated using as-synthesized leaf-shaped $\mathrm{CuO}$ nanosheets. At the optimized temperature conditions, a gas response of 35.3 was observed for 200 ppm $\mathrm{H}_{2} \mathrm{~S}$ gas. Outstanding linearity between gas response and the concentrations of the $\mathrm{H}_{2} \mathrm{~S}$ gas were shown at low as well as high concentration ranges. Additionally, the fabricated sensors also showed good repeatability and selectivity. The excellent gas response for leaf-shaped $\mathrm{CuO}$ nanosheets gas sensors are due to the unique nanosheet-like morphology for of $\mathrm{CuO}$ which provide a large specific surface area for the high extent of adsorption of $\mathrm{O}_{2}$ and $\mathrm{H}_{2} \mathrm{~S}$ gas molecules. From these findings, it can be presumed that gas 
sensors based on leaf-shaped $\mathrm{CuO}$ nanosheets may, in near future, be suitable materials for the detection of highly toxic gases like $\mathrm{H}_{2} \mathrm{~S}$.

Author Contributions: Author Contributions: Conceptualization, A.U., H.A. (Hassan Algadi), M.S.A., A.A.I. and W.Z.; methodology, A.U., H.A. (Hassan Algadi), M.S.A., A.A.I., H.A. (Hasan Albargi) and W.Z.; software, A.U., H.A. (Hassan Algadi), R.K., M.S.A., A.A.I., H.A. (Hasan Albargi), and M.A.M.A.; formal analysis, A.U., H.A.(Hassan Algadi), R.K., M.S.A., A.A.I., H.A. (Hasan Albargi), M.A.M.A., T.A. and W.Z.; investigation, A.U., H.A. (Hassan Algadi), R.K., M.S.A., A.A.I., H.A. (Hasan Albargi), M.A.M.A., T.A. and W.Z. writing - original draft preparation, A.U. R.K., M.S.A.; writing-review and editing, A.U., R.K., M.S.A. and W.Z. All authors have read and agreed to the published version of the manuscript.

Funding: This research was funded by the Deputy for Research and Innovation-Ministry of Education, Kingdom of Saudi Arabia through a grant (NU/IFC/INT/01/004) under the institutional funding committee at Najran University, Kingdom of Saudi Arabia.

Institutional Review Board Statement: Not applicable.

Informed Consent Statement: Not applicable.

Data Availability Statement: Data is contained within the article.

Acknowledgments: Authors would like to acknowledge the support of the Deputy for Research and Innovation-Ministry of Education, Kingdom of Saudi Arabia for the research through a grant (NU/IFC/INT/01/004) under the institutional funding committee at Najran University, Kingdom of Saudi Arabia.

Conflicts of Interest: The authors declare no conflict of interest.

\section{References}

1. Umar, A.; Alduraibi, M.; Al-Dossary, O. NOx Gas Sensing Properties of Fe-Doped ZnO Nanoparticles. Sci. Adv. Mater. 2020, 12, 908-914. [CrossRef]

2. Sampaolo, A.; Yu, C.; Wei, T.; Zifarelli, A.; Giglio, M.; Patimisco, P.; Zhu, H.; Zhu, H.; He, L.; Wu, H.; et al. H ${ }_{2}$ S quartz-enhanced photoacoustic spectroscopy sensor employing a liquid-nitrogen-cooled THz quantum cascade laser operating in pulsed mode. Photoacoustics 2021, 21, 100219. [CrossRef]

3. Wu, C.; Ye, G.; Qi, L.; Wang, Y.; Yuan, C.; Zhang, L. Novel ZnO Sensor and Gas Detection Performance in Tunnel Construction. J. Nanoelectron. Optoelectron. 2020, 15, 1114-1119. [CrossRef]

4. Zhu, M.; Zhang, L. A Novel H 2 S Gas Sensor Applied to the Construction Workers During the Construction Process. Sci. Adv. Mater. 2018, 11, 143-146. [CrossRef]

5. Zhang, S.; Liu, Z.; Zhang, L.; Chen, J.; Zhou, Q.; Zhang, H.; Nie, L.; Dong, Z.; Zhang, Z.; Wang, Z.; et al. Construction of a low-temperature, highly sensitive $\mathrm{H}_{2} \mathrm{~S}$ sensor based on surfaces and interfaces reaction triggered by Au-doped hierarchical structured composites. Chem. Phys. Lett. 2021, 763, 138188. [CrossRef]

6. Wu, C.; Yuan, C.; Qi, L.; Wang, Y.; Guo, Y. A Novel Hydrogen Sulfide Gas Sensor Apply in Tunnel Construction. Sci. Adv. Mater. 2018, 11, 112-115. [CrossRef]

7. Li, Z.-Y.; Wu, G.; Chen, J.-Y.; Li, W.-C. A Novel Gas Sensor Detection of Hydrogen Sulfide in Tunnel Construction. Sci. Adv. Mater. 2018, 11, 147-151. [CrossRef]

8. Pravarthana, D.; Tyagi, A.; Jagadale, T.C.; Prellier, W.; Aswal, D.K. Highly sensitive and selective $\mathrm{H} 2 \mathrm{~S}$ gas sensor based on TiO2 thin films. Appl. Surf. Sci. 2021, 549, 149281. [CrossRef]

9. Cho, M.; Eom, T.; Nundy, S.; Park, J.-S.; Lee, H.-J. Conductometric nitrogen dioxide gas sensors based on sol-gel-prepared hafnium-added indium zinc oxide (Hf-IZO). Sens. Actuators B Chem. 2021, 344, 130198. [CrossRef]

10. Pi, M.; Zheng, C.; Bi, R.; Zhao, H.; Liang, L.; Zhang, Y.; Wang, Y.; Tittel, F.K. Design of a mid-infrared suspended chalcogenide/silica-on-silicon slot-waveguide spectroscopic gas sensor with enhanced light-gas interaction effect. Sens. Actuators B Chem. 2019, 297, 126732. [CrossRef]

11. Bao, Y.; Xu, P.; Cai, S.; Yu, H.; Li, X. Detection of volatile-organic-compounds (VOCs) in solution using cantilever-based gas sensors. Talanta 2018, 182, 148-155. [CrossRef]

12. Lee, J.H.; Park, M.S.; Jung, H.; Choe, Y.-S.; Kim, W.; Song, Y.G.; Kang, C.-Y.; Lee, H.-S.; Lee, W. Selective $\mathrm{C}_{2} \mathrm{H}_{2}$ detection with high sensitivity using $\mathrm{SnO}_{2}$ nanorod based gas sensors integrated with a gas chromatography. Sens. Actuators B Chem. 2020, 307, 127598. [CrossRef]

13. Maurya, J.B.; Prajapati, Y.K.; Raikwar, S.; Saini, J.P. A silicon-black phosphorous based surface plasmon resonance sensor for the detection of $\mathrm{NO}_{2}$ gas. Optik 2018, 160, 428-433. [CrossRef]

14. Grabka, M.; Jasek, K.; Pasternak, M. Application of polymethyl [4-(2,3-difluoro-4-hydroxyphenoxy) butyl] siloxane in surface acoustic wave gas sensors for dimethyl methylphosphonate detection. Sens. Actuators B Chem. 2021, 329, 129216. [CrossRef] 
15. Zhang, P.; Xiao, Y.; Zhang, J.; Liu, B.; Ma, X.; Wang, Y. Highly sensitive gas sensing platforms based on field effect Transistor-A review. Anal. Chim. Acta 2021, 1172, 338575. [CrossRef] [PubMed]

16. Zhong, Z.-C.; Han, X.; Liu, K.-Y.; Xu, Y.; Lin, J. Rapid and Sensitive Acetylene Gas Sensor Based on TiO 2 Nanoparticles. Sci. Adv. Mater. 2019, 11, 1126-1132. [CrossRef]

17. Zhou, M.; Chen, X.; Zhang, L.; Zeng, W. High Performance Novel Gas Sensor Device for Site Environmental Protection Using Ti 0.5 Sn 0.5 O 2 Nanomaterials. J. Nanoelectron. Optoelectron. 2021, 15, 1423-1428. [CrossRef]

18. Shaik, M.; Rao, V.K.; Gupta, M.; Murthy, K.S.R.C.; Jain, R. Chemiresistive gas sensor for the sensitive detection of nitrogen dioxide based on nitrogen doped graphene nanosheets. RSC Adv. 2016, 6, 1527-1534. [CrossRef]

19. Qiao, X.; Xu, Y.; Yang, K.; Ma, J.; Li, C.; Wang, H.; Jia, L. Mo doped $\mathrm{BiVO}_{4}$ gas sensor with high sensitivity and selectivity towards $\mathrm{H}_{2}$ S. Chem. Eng. J. 2020, 395, 125144. [CrossRef]

20. Li, S.; Xie, L.; He, M.; Hu, X.; Luo, G.; Chen, C.; Zhu, Z. Metal-Organic frameworks-derived bamboo-like CuO/ $\mathrm{In}_{2} \mathrm{O}_{3} \mathrm{Het}_{-}$ erostructure for high-performance $\mathrm{H}_{2} \mathrm{~S}$ gas sensor with Low operating temperature. Sens. Actuators B Chem. 2020, $310,127828$. [CrossRef]

21. Hosseini, Z.S.; Iraji zad, A.; Mortezaali, A. Room temperature $\mathrm{H}_{2} \mathrm{~S}$ gas sensor based on rather aligned $\mathrm{ZnO}$ nanorods with flower-like structures. Sens. Actuators B Chem. 2015, 207, 865-871. [CrossRef]

22. Shewale, P.S.; Yun, K.-S. Synthesis and characterization of $\mathrm{Cu}$-doped $\mathrm{ZnO} / \mathrm{RGO}$ nanocomposites for room-temperature $\mathrm{H} 2 \mathrm{~S}$ gas sensor. J. Alloy. Compd. 2020, 837, 155527. [CrossRef]

23. Haija, M.A.; Abu-Hani, A.F.S.; Hamdan, N.; Stephen, S.; Ayesh, A.I. Characterization of H2S gas sensor based on CuFe2O4 nanoparticles. J. Alloy. Compd. 2017, 690, 461-468. [CrossRef]

24. Ighalo, J.O.; Sagboye, P.A.; Umenweke, G.; Ajala, O.J.; Omoarukhe, F.O.; Adeyanju, C.A.; Ogunniyi, S.; Adeniyi, A.G. CuO nanoparticles (CuO NPs) for water treatment: A review of recent advances. Environ. Nanotechnol. Monit. Manag. 2021, 15, 100443. [CrossRef]

25. Zhu, W.; An, X.; Huangfu, W.; Chi, J.; Xu, L. A Novel CuO flower like nanomaterials and its fault detection performance in power cable. J. Nanoelectron. Optoelectron. 2020, 15, 1146-1150.

26. Yang, C.; Xiao, F.; Wang, J.; Su, X. 3D flower- and 2D sheet-like CuO nanostructures: Microwave-assisted synthesis and application in gas sensors. Sens. Actuators B Chem. 2015, 207, 177-185. [CrossRef]

27. Hu, Q.; Zhang, W.; Wang, X.; Wang, Q.; Huang, B.; Li, Y.; Hua, X.; Liu, G.; Li, B.; Zhou, J.; et al. Binder-free CuO nanoneedle arrays based tube-type sensor for $\mathrm{H}_{2} \mathrm{~S}$ gas sensing. Sens. Actuators B Chem. 2021, 326, 128993. [CrossRef]

28. Yang, C.; Su, X.; Xiao, F.; Jian, J.; Wang, J. Gas sensing properties of CuO nanorods synthesized by a microwave-assisted hydrothermal method. Sens. Actuators B Chem. 2011, 158, 299-303. [CrossRef]

29. Kim, J.H.; Katoch, A.; Choi, S.W.; Kim, S.S. Growth and sensing properties of networked p-CuO nanowires. Sens. Actuators $B$ Chem. 2015, 212, 190-195. [CrossRef]

30. Umar, A.; Alshahrani, A.A.; Algarni, H.; Kumar, R. CuO nanosheets as potential scaffolds for gas sensing applications. Sens. Actuators B Chem. 2017, 250, 24-31. [CrossRef]

31. Chaloeipote, G.; Prathumwan, R.; Subannajui, K.; Wisitsoraat, A.; Wongchoosuk, C. 3D printed CuO semiconducting gas sensor for ammonia detection at room temperature. Mater. Sci. Semicond. Process. 2021, 123, 105546. [CrossRef]

32. Rezaei, K.; Nasirian, S. A low-level acetone gas sensor based on n-type $\mathrm{ZnO} / \mathrm{p}$-type $\mathrm{CuO}$ composite nanostructure for the diagnosis of diabetes in dynamic situations. J. Mater. Sci. Mater. Electron. 2021, 32, 5199-5214. [CrossRef]

33. Wang, F.; Li, H.; Yuan, Z.; Sun, Y.; Chang, F.; Deng, H.; Xie, L.; Li, H. A highly sensitive gas sensor based on CuO nanoparticles synthetized via a sol-gel method. RSC Adv. 2016, 6, 79343-79349. [CrossRef]

34. Singh, S.; Verma, N.; Singh, A.; Yadav, B.C. Synthesis and characterization of $\mathrm{CuO}-\mathrm{SnO}_{2}$ nanocomposite and its application as liquefied petroleum gas sensor. Mater. Sci. Semicond. Process. 2014, 18, 88-96. [CrossRef]

35. Liao, L.; Zhang, Z.; Yan, B.; Zheng, Z.; Bao, Q.L.; Wu, T.; Li, C.M.; Shen, Z.X.; Zhang, J.X.; Gong, H.; et al. Multifunctional CuO nanowire devices: P-type field effect transistors and CO gas sensors. Nanotechnology 2009, 20, 085203. [CrossRef] [PubMed]

36. Bai, B.C.; Lee, C.W.; Lee, Y.-S.; Im, J.S. Modification of textural properties of CuO-supported activated carbon fibers for $\mathrm{SO}_{2}$ adsorption based on electrical investigation. Mater. Chem. Phys. 2017, 200, 361-367. [CrossRef]

37. Li, Z.; Liu, Y.; Guo, D.; Guo, J.; Su, Y. Room-temperature synthesis of CuO/reduced graphene oxide nanohybrids for highperformance NO2 gas sensor. Sens. Actuators B Chem. 2018, 271, 306-310. [CrossRef]

38. Cunniff, C.Z.; Specht, S.E.; Love, A.M.; Uchupalanun, P.; Venegas, J.M.; Kruszynski, C.E.; Hermans, I. Investigation of supported metal oxide species with shell-isolated nanoparticle-enhanced Raman spectroscopy. J. Phys. Chem. C 2019, 123, 25220-25227. [CrossRef]

39. Debbichi, L.; Marco de Lucas, M.C.; Pierson, J.F.; Krüger, P. Vibrational Properties of $\mathrm{CuO}$ and $\mathrm{Cu}_{4} \mathrm{O}_{3}$ from First-Principles Calculations, and Raman and Infrared Spectroscopy. J. Phys. Chem. C 2012, 116, 10232-10237. [CrossRef]

40. Umar, A.; Ibrahim, A.A.; Ammar, H.Y.; Nakate, U.T.; Albargi, H.B.; Hahn, Y.B. Urchin like CuO hollow microspheres for selective high response ethanol sensor application: Experimental and theoretical studies. Ceram. Int. 2021, 47, 12084-12095. [CrossRef]

41. Umar, A.; Ibrahim, A.A.; Nakate, U.T.; Albargi, H.; Alsaiari, M.A.; Ahmed, F.; Alharthi, F.A.; Ali Alghamdi, A.; Al-Zaqri, N. Fabrication and characterization of $\mathrm{CuO}$ nanoplates based sensor device for ethanol gas sensing application. Chem. Phys. Lett. 2021, 763, 138204. [CrossRef] 
42. Rashad, M.; Rüsing, M.; Berth, G.; Lischka, K.; Pawlis, A. $\mathrm{CuO}$ and $\mathrm{Co}_{3} \mathrm{O}_{4}$ nanoparticles: Synthesis, characterizations, and raman spectroscopy. J. Nanomater. 2013, 2013, 714853. [CrossRef]

43. Veisi, H.; Karmakar, B.; Tamoradi, T.; Hemmati, S.; Hekmati, M.; Hamelian, M. Biosynthesis of CuO nanoparticles using aqueous extract of herbal tea (Stachys Lavandulifolia) flowers and evaluation of its catalytic activity. Sci. Rep. 2021, 11, 1983. [CrossRef] [PubMed]

44. Jadhav, M.S.; Kulkarni, S.; Raikar, P.; Barretto, D.A.; Vootla, S.K.; Raikar, U.S. Green biosynthesis of CuO \& Ag-CuO nanoparticles from Malus domestica leaf extract and evaluation of antibacterial, antioxidant and DNA cleavage activities. New J. Chem. 2018, 42, 204-213. [CrossRef]

45. Huang, C.-Y.; Chatterjee, A.; Liu, S.B.; Wu, S.Y.; Cheng, C.-L. Photoluminescence properties of a single tapered CuO nanowire. Appl. Surf. Sci. 2010, 256, 3688-3692. [CrossRef]

46. Sagadevan, S.; Pal, K.; Chowdhury, Z.Z. Fabrication of $\mathrm{CuO}$ nanoparticles for structural, optical and dielectric analysis using chemical precipitation method. J. Mater. Sci. Mater. Electron. 2017, 28, 12591-12597. [CrossRef]

47. Lupan, O.; Postica, V.; Cretu, V.; Wolff, N.; Duppel, V.; Kienle, L.; Adelung, R. Single and networked CuO nanowires for highly sensitive p-type semiconductor gas sensor applications. Phys. Status Solidi Rapid Res. Lett. 2016, 10, 260-266. [CrossRef]

48. Zhang, F.; Zhu, A.; Luo, Y.; Tian, Y.; Yang, J.; Qin, Y. CuO nanosheets for sensitive and selective determination of $\mathrm{H}_{2} \mathrm{~S}$ with high recovery ability. J. Phys. Chem. C 2010, 114, 19214-19219. [CrossRef]

49. Li, Z.; Wang, N.; Lin, Z.; Wang, J.; Liu, W.; Sun, K.; Fu, Y.Q.; Wang, Z. Room-temperature high performance $\mathrm{H}_{2} \mathrm{~S}$ sensor based on porous $\mathrm{CuO}$ nanosheets prepared by hydrothermal method. ACS Appl. Mater. Interfaces 2016, 8, 20962-20968. [CrossRef]

50. Kim, J.-H.; Mirzaei, A.; Zheng, Y.; Lee, J.-H.; Kim, J.-Y.; Kim, H.W.; Kim, S.S. Enhancement of $\mathrm{H}_{2} \mathrm{~S}$ sensing performance of p-CuO nanofibers by loading p-reduced graphene oxide nanosheets. Sens. Actuators B Chem. 2019, 281, 453-461. [CrossRef]

51. Li, Z.; Wang, J.; Wang, N.; Yan, S.; Liu, W.; Fu, Y.Q.; Wang, Z. Hydrothermal synthesis of hierarchically flower-like CuO nanostructures with porous nanosheets for excellent $\mathrm{H}_{2} \mathrm{~S}$ sensing. J. Alloy. Compd. 2017, 725, 1136-1143. [CrossRef]

52. Kim, S.-J.; Na, C.W.; Hwang, I.-S.; Lee, J.-H. One-pot hydrothermal synthesis of CuO-ZnO composite hollow spheres for selective $\mathrm{H}_{2} \mathrm{~S}$ detection. Sens. Actuators B Chem. 2012, 168, 83-89. [CrossRef]

53. Sui, L.; Yu, T.; Zhao, D.; Cheng, X.; Zhang, X.; Wang, P.; Xu, Y.; Gao, S.; Zhao, H.; Gao, Y.; et al. In Situ deposited hierarchical $\mathrm{CuO} / \mathrm{NiO}$ nanowall arrays film sensor with enhanced gas sensing performance to $\mathrm{H}_{2} \mathrm{~S}$. J. Hazard. Mater. 2020, 385, 121570. [CrossRef] [PubMed]

54. Zhang, D.; $\mathrm{Wu}$, J.; Cao, Y. Ultrasensitive $\mathrm{H}_{2} \mathrm{~S}$ gas detection at room temperature based on copper oxide/molybdenum disulfide nanocomposite with synergistic effect. Sens. Actuators B Chem. 2019, 287, 346-355. [CrossRef] 